\title{
Microhardness and Chemical Composition of Human Tooth
}

\author{
Maria del Pilar Gutiérrez-Salazar ${ }^{\mathrm{a}, \mathrm{b}}$, Jorge Reyes-Gasga ${ }^{\mathrm{a}}$ * \\ ${ }^{a}$ Instituto de Física, UNAM; Apdo. Postal 20-364, 01000 México D.F., México \\ ${ }^{\mathrm{b}}$ Facultad de Odontología, UNAM; Circuito de la Investigación $s / n$. Cd. Universitaria, \\ 04510 Coyoacán, México D.F., México
}

Received: November 15, 2002; Revised: June 2, 2003

\begin{abstract}
Hardness of human tooth, both in enamel and dentin, has been measured at different sites using a Vicker's diamond. In this work we show that these values are almost constant all along the enamel and dentin thicknesses. Indentations were done from outer enamel surface to inner dentin layer, going through the enamel-dentin junction, both in transverse and longitudinal samples. Geometrical well-shape indentation uniformity was checked both with light and with scanning electron microscopes, and the chemical composition of the tooth was analyzed with characteristic $\mathrm{X}$-ray energy dispersive spectroscopy. Hardness measurements were in the range from 270 to $360 \mathrm{VHN}$ for enamel and 50 to $60 \mathrm{VHN}$ for dentin. Cervical zone in longitudinal section showed the lowest value while in transverse sections the highest. All the hardness values were statically significative. Tour results indicate that the difference between enamel and dentin hardness has nothing to do with the content of $\mathrm{Na}, \mathrm{Cl}$ and $\mathrm{Mg}$, but the percentage of organic and inorganic materials in enamel and dentin.
\end{abstract}

Keywords: microhardness, chemical composition, human tooth, enamel, dentin

\section{Introduction}

Tooth enamel is the most mineralized tissue of human body. Its composition is $96 \mathrm{wt} \%$ inorganic material and $4 \mathrm{wt} \%$ organic material and water. In dentin, the inorganic material represents $70 \mathrm{wt} \%$. This inorganic material is mainly composed by a calcium phosphate related to the hexagonal hydroxyapatite, whose chemical formula is $\mathrm{Ca}_{10}\left(\mathrm{PO}_{4}\right)_{6} \cdot 2(\mathrm{OH})^{1}$. X-ray energy dispersive spectroscopy (EDS) analysis of enamel and dentin also indicated the presence in small quantities of other elements such as $\mathrm{Na}, \mathrm{Cl}$ and $\mathrm{Mg}^{2}$.

Human teeth are exposed to a different point-to-point pressure during mastication. Therefore, the study and analysis of their hardness is very important for understanding how masticatory strains are distributed throughout the tooth, and for predicting how stresses and strains are altered by dental restorative procedures, age and disease. Moreover, the hardness values can be related to other mechanical properties, such as Young's modulus and yield stress ${ }^{3,4}$. Measurement of hardness in tooth is not easy, however. Because the structures that enamel ${ }^{2}$ and dentin present, prisms running from the enamel-dentin junction (EDJ) to the surface in the case of enamel and a heterogeneous composite material in the case of dentin ${ }^{5-7}$, it is easy to imagine that their hardness values are different, even from one site to other inside enamel and dentin themselves; and that they would be chemically dependent.

Hardness testing, together with intra-oral models, has great importance in de- and re-mineralization experiments ${ }^{8}$. The hardness of human tooth has been determined by a variety of methods, including abrasion ${ }^{9}$, scratch ${ }^{10}$, and indentation techniques $^{3,4,11-14}$. Since considerable local variations have been reported in enamel and dentin, the methods using a microscratch or micro-indentation have been preferred, and the Knoop diamond indenter is commonly used ${ }^{4,8,13,14}$. Recently, nano-indentation using atomic force microscopy was reported in hardness measurements of dentin ${ }^{3}$.

Knoop (KHN) and Vicker (VHN) hardnesses have reported approximately the same value ${ }^{15}$. The average hardness value for enamel and dentin is in the range from 270 to $350 \mathrm{KHN}$ (or from 250 to $360 \mathrm{VHN}$ ) and from 50 to $70 \mathrm{KHN}$ respectively ${ }^{4}$. However, the standard deviations (SD) for these values show broad and significative variations, although in dentin these variations are less pronounced. Thus,

*e-mail: jreyes@ fisica.unam.mx

Trabalho apresentado no $1^{\circ}$ Congresso da Sociedade Brasileira em Materiais, Rio de Janeiro, Julho de 2002. 
for example, Craig and Peyton ${ }^{13}$ reported for enamel a hardness in the range from $344 \pm 49$ to $418 \pm 60 \mathrm{VHN}$; Collys et al. ${ }^{14}$ from $369 \pm 25$ to $431 \pm 35$; Wilson and Love ${ }^{16}$ from $263 \pm 26$ to $327 \pm 40$. The micro-hardness of the occlusal enamel varied from 359 to $424 \mathrm{VHN}$, and that of the cervical enamel from 227 to $342 \mathrm{VHN}^{14}$. These variations can be produced by factors such as histology features, chemical composition, specimen preparation, and load and reading error in indentation length (IL).

In sound human enamel, it was reported that the hardness values, the mineral content, and the density gradually decrease from the outer surface to the EDJ ${ }^{18-22}$. More specific, Kodaka et al. ${ }^{19}$ found a moderate correlation between the Vicker hardness and $\mathrm{P}$ concentration in enamel, but a low correlation with $\mathrm{Ca}$. They indicated that VHN values, $\mathrm{Ca}$ and $\mathrm{P}$ percentage significantly decreased in the outer, middle and inner enamel sites. Other studies ${ }^{11,19}$ reported that the outer enamel surface is harder than the inner surface, and that hardness continuously decreases from the outer edge to EDJ. Gustafson and Kling ${ }^{21}$ proposed that the differences of hardness in enamel can be produced by variations in the direction of indentations in a single tooth section. However, some other studies ${ }^{13}$ have found any difference at all, only slight indications that enamel is harder in the cusp and outer surface than in the cervical margin or EDJ, but the difference was less than the SD reported, and thus no definite statement can be made.

Hardness numbers reported for dentin also varies. Because of the larger size of the indentation in relation to the dentin microstructure, this variation may be due to the differences in the dentinal tubule density at different locations. Kenney et al. ${ }^{3}$, using a modified atomic-force microscope to measure the hardness of dentin, indicated that hydrated peritubular dentin has a hardness inside the range from 2.2 to $2.5 \mathrm{GPa}$ independent of location, while in intertubular dentin this hardness did depend upon location, and it was significantly greater near the EDJ (values from 0.49 to $0.52 \mathrm{GPa}$ ) than near the pulp (from 0.12 to $0.18 \mathrm{GPa}$ ).

Another parameter that must be taken into account in is time. It was reported that in human tooth the hardness indentations restored after time ${ }^{13,22}$. However, in general, little is known about the way the size of these indentations changes with time. Since enamel is a rather brittle material, time dependency of an indentation seems to be very small or negligible. But, in dentin, Herkstroter et al. ${ }^{22}$ found that indentations relaxed (becomes smaller) over a period of one day; after that the indentations do not change statistically anymore. Some explanation for indentation relaxation could be the differences in the content of organic matrix and/or in the bonding between mineral and organic matrix.

As it can be seen, too many parameters are involved in the analysis of human tooth hardness; therefore, in this work we obtain accurate Vickers hardness values (with minimum SD) for enamel and dentin in sound teeth. We took care of the sample preparation method, the chemical composition all along the tooth, and the relative orientation of the indenter with the enamel prisms and dentin tubules to identify and control the parameters that statistically affect the hardness measurement. Vickers hardness indentations were measured and analyzed with light microscopy (LM) and scanning electron microscopy (SEM).

\section{Experimental procedure}

Seven mature, sound premolars freshly extracted by orthodontic reasons were embedded in self-curing resin (Fig. 1). The embedded teeth were sectioned either transversely or longitudinally (Fig. 1: a, $A_{2}$ ) using diamond wheel cutter Whiler Mod. Cutto-1. Three teeth were sectioned parallel to the occlusal surface, making cuts close to $0.5 \mathrm{~mm}$ from the cuspid, $1.5 \mathrm{~mm}$ in the cusp, in the medium third, and the cervical third (Fig 1: c, d, e). The others were sectioned bucolingually perpendicular to the mesiodistal axis of the tooth (Fig. 1: $\mathrm{A}_{1}$ ).

One of the factors that affect the hardness measurement is the specimen preparation, because any tilt or not flat surface would yield a too large IL and thus a smaller VHN value. Therefore, to produce a flat surface in the specimens is crucial in this analysis. With this in mind, the specimens were polished with silicon carbide papers from $\mathrm{n}^{\mathrm{o}} 1200$ to 4000 , in a progressively way, with water. Final polish was done with 0.05 polishing alumina in a low-speed metallurgical polisher Buehler, mod. Minimet, with light load on the specimen. Afterwards, the samples were cleaned by three periods of 5 min each with distilled water inside on ultrasonic cleaner Bransonic mod. 52.

Vicker hardness measurements were made with a micro-hardness tester Matsuzawa mod. MHT2 with a square based diamond indenter with $136^{\circ}$ angle. This tester has a light microscope of high resolution and contrast with magnification of $400 \times$. Indentations were made with a rate of $20 \mathrm{~s}$ descending and loads of $10 \mathrm{~g}, 25 \mathrm{~g}$, and $50 \mathrm{~g}$; and never close to any edge of the specimen or another indentation. The minimum distance between two consecutive indentations was bigger than $40 \mu \mathrm{m}$. The number of indentations made in a location of the tooth depended on the enamel and dentin thicknesses at such level. Therefore, this number was bigger in the cusp zone than in the cervical zone (Fig. 2). Criteria for accepting an indentation were sharpness of diagonal edges, uniformity of diagonal shape (geometry) and free of irregularities in the testing area. In longitudinal samples, the indentations were done from the enamel outer surface to dentin inner surface, going through EDJ in five zones: cervical, middle third, cusp, grove, and parallel to occlusal (Fig. 2). In transverse samples, they were done in bucolingual to mesiodistal direction (Fig. 1: $\mathrm{A}_{2}$ ). 


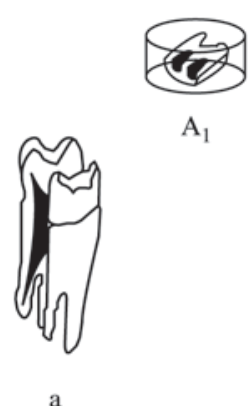

a
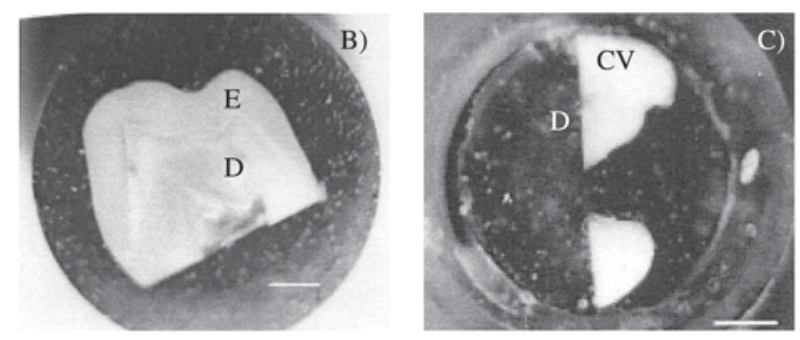

Figure 1. A) Cutting of the human tooth and preparation of the samples for hardness measurements. a) Longitudinal cut; b) resin embedding; $A_{1}$ ) longitudinal sample; $A_{2}$ ) transverse sample (c-e). B) Light microscope image of section $A_{1}$. C) Light microscope image of section $\mathrm{A}_{2}(\mathrm{~d})$.

$\mathrm{E}=$ enamel, $\mathrm{D}=$ dentin, $\mathrm{CV}=$ vestibular cusp. $\mathrm{Bar}=2 \mathrm{~mm}$.

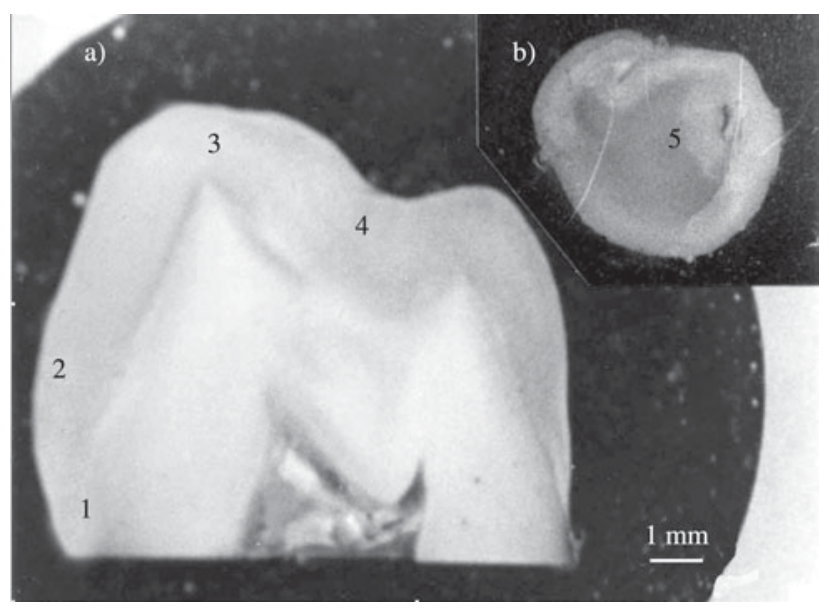

Figure 2. Human tooth cuts where the Vicker's hardness indentations where carried out. a) Longitudinal section; b) transverse section. The numbers indicate the zones under analysis: cervical (1), middle third (2), cusp (3), grove (4), and parallel to occlusal (5).

The length of the axes of the squared-shaped indentation (IL) was read either with the micrometer scale fitted to the eyepiece of the hardness tester, with other light microscope (LM), and with SEM. The VHN value was obtained from tables. The mean value and SD were calculated for both IL and VHN. Kappa statistics was used to assessment the reliability of the observer error in reading IL. A Kappa value of 0.90 was achieved. To reduce errors, the same observer made the reading. The Zeiss Axiotech LM and Jeol 5200 SEM microscopes were used for these observations. The results were analyzed comparing the diagonal indentation length values using the variance analysis ANOVA. For the EDS chemical analysis, a Philips XL30 SEM with a NORAN-EDS detector, was used.

\section{Results}

Figure 3 shows some of the main indentation irregularities produced in human teeth when some experimental parameters are not adequate; they are an indication that the sample preparation method, or the load, and/or the position of the indentation are not the correct ones. Any of these irregularities allow the correct measurement of IL, and, therefore, in this work, when one of them was observed, the sample was not used for hardness measurement. In fact, observation of any of these irregularities was enough for re-checking preparation and experimental procedures of the sample under analysis.

Figure 4 shows shape of the VHN indentations that cover all the requirements for hardness measurements. Figure $4 \mathrm{a}$ shows an example of indentations produced through all the tooth thickness in a cusp longitudinal sample. Figure $4 \mathrm{~b}$ shows some of the indentation produced in enamel, while Fig. $4 \mathrm{c}$ shows one in dentin. Magnification in Figs. $4 \mathrm{~b}$ and $4 \mathrm{c}$ is the same, so the hardness difference in enamel and dentin is straightforward. Figure 4 also allows the comparison between the indentation size and the enamel prisms size: this indicates an indentation area of $25 \mu \mathrm{m}^{2}$.

To avoid indentations such as those shown in Fig. 3, the sample preparation method was perfected and the analysis with loads of 10,25 , and $50 \mathrm{~g}$ was carried out. The mean values for IL produced with these loads in the same zone and their corresponding VHN values are shown in Table 1. Taking in account the SD in each case, the similarity of the VHN values in the zone analyzed is straightforward. However SD for loads of 10 and $50 \mathrm{~g}$ are bigger than that for $25 \mathrm{~g}$.

Collys et al. ${ }^{14}$ suggested a load of $50 \mathrm{~g}$ for studies of hardness in tooth because they said that lower loads influence the indentation size. They indicated two aspects for this load influence: 1) the sample surface is altered during the polish process producing a coating bigger than the biggest depth reached for the indenter; and 2) with lower loads, the difficulty to read the indentation marks increase. However, in this work we did not observe, after the sample preparation method followed, any coating layer; eventhough, the enamel and dentin structure is always observed (Fig. 4). 


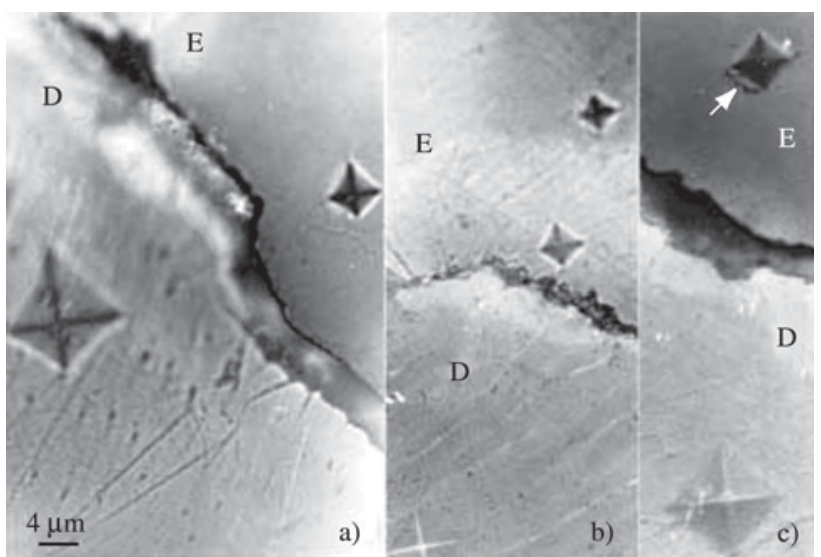

Figure 3. Light microscope images of the irregularities commonly observed in the hardness indentation of the human tooth produced by non-flat surfaces. For those on/or close the EDJ $(a, b)$ the deformation is produced by the difference in hardness of enamel and dentin. Some indentations showed some cracking and accumulation of material around it (c, indicated by the arrow).

E: enamel; D: dentin.

The depth reached with the square based diamond indenter used was of $2 \mu \mathrm{m}$ approximately. Moreover, with the load of $50 \mathrm{~g}$ almost all the indentations showed fractures and material accumulation, such as those shown in Fig. 3. With the load of $10 \mathrm{~g}$ the indentations were very difficult to read.

The hardness values obtained with both 25 and $50 \mathrm{~g}$ were statistically similar, but load of $25 \mathrm{~g}$ produced less fracture indications and better indentation shapes. Therefore, after the analysis of Table 1, and taking in account all above said, the load of $25 \mathrm{~g}$ was chosen for the hardness measurements. Occasionally some slight fractures were observed in the outer edge of the grove zone (zone 4) and in the middle third (zone 2), close to the vestibular surface, but not in any of the others. Time of load application is another parameter that we studied. $\mathrm{McColm}^{23}$ indicated that 15 to $30 \mathrm{~s}$ are quite recommended for ceramic materials. Therefore we applied the load of $25 \mathrm{~g}$ during $20 \mathrm{~s}$ for this study.

Figure 2 shows the different levels of the human tooth where the Vicker hardness indentations where carried out. Table 2 shows the main VHN values obtained with the load of $25 \mathrm{~g}$ at the different tooth zones evaluated. This table indicates that the zone corresponding to the transverse section parallel to occlusal (zone 5) showed the biggest hardness values, whereas zone 1 (cervical) showed the lowest. Note that, however, taking in account the SD values, the difference in hardness between of zone 1 and zone 5 is minimum. Table 3 shows the main VHN values obtained from the different zones evaluated. Here we observe that hardness in enamel is higher than in dentin, as expected, but it

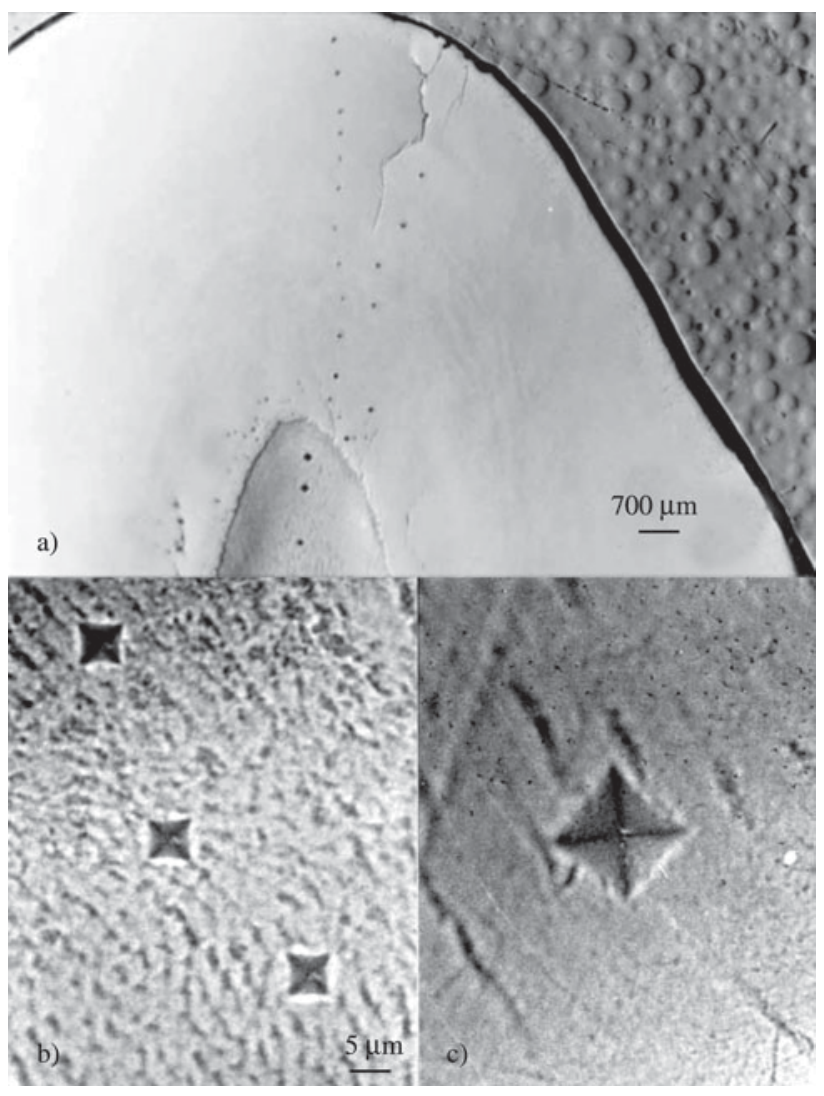

Figure 4. Light microscope images of well-shaped indentations in enamel. They present good shapes to obtain the VHN values of human tooth because both diagonals have the same length and they are straightly reading. a) Sequence of indentations through enamel, EDJ, and dentin corresponding to the cusp zone (zone 3); b) Indentations in enamel; c) indentation in dentin.

remains almost constant in all the enamel and dentin thicknesses respectively. Only close to the EDJ there is a gap where it decreases from enamel's value to dentin's value.

From the data obtained, the zone with the minimum VHN value was zone 2 (the middle third) while the biggest was the zone 5 (parallel to the occlusal). In general, indentations in the transverse section samples where more easily reading, with very good shape and with minimum fracture mark. In the other hand, in longitudinal section the indentations showed some indication of fracture, especially those of zone 2. Statistically speaking, the results obtained by ANOVA showed significative differences $(p>0.05)$ among the zone 5 and the others. From this, it is concluded that zone 5 showed the significatively bigger hardness value, whereas zone 1 showed the lowest.

The chemical analysis by EDS indicated that the $\mathrm{Ca} / \mathrm{P}$ relationship was bigger in enamel than dentin. In enamel it was around 1.63 , compared with 1.67 in pure hydroxyapa- 
Table 1. Vicker's hardness number (VHN) and indentation length (IL) for different loads in the same tooth zone. Mean values and standard deviations (SD) for IL and VHN are shown. $\mathrm{N}$ is the number of indentations, taken from the 7 samples, and taken in account for statistics. Note the increment of SD for $10 \mathrm{~g}$, because the error in IL measurement is bigger, and $50 \mathrm{~g}$, because excessive load.

\begin{tabular}{cccc}
\hline Load $(\mathrm{g})$ & $\mathrm{N}$ & $\mathrm{IL} \mu \mathrm{m}( \pm \mathrm{SD})$ & $\mathrm{VHN}( \pm \mathrm{SD})$ \\
\hline 10 & 15 & $8.20( \pm 0.24)$ & $276( \pm 19.03)$ \\
25 & 9 & $12.60( \pm 0.17)$ & $292( \pm 09.67)$ \\
50 & 10 & $17.30( \pm 0.61)$ & $310( \pm 24.83)$ \\
\hline
\end{tabular}

Table 2. Vicker's hardness number (VHN) and indentation length (IL) for the five analyzed zones from the 7 samples analyzed. Mean values and standard deviation (SD) for IL and VHN are shown. N is the number of indentations taken from the 7 samples, and taken in account for statistics. These data was obtained with a load of $25 \mathrm{~g}$. Note the small variations in VHN values for the first four zones when $\mathrm{SD}$, indicated by $(*)$, is taken in account. The parallel to occlusal zone presents the bigger VHN value.

\begin{tabular}{lccc}
\hline Zone & $\mathrm{N}$ & $\mathrm{IL} \mu \mathrm{m}( \pm \mathrm{SD})$ & $\mathrm{VHN}(*)$ \\
\hline 1. Cervical & 55 & $13.06( \pm 1.19)$ & $270(230-279)$ \\
2. Middlethird & 114 & $12.51( \pm 0.45)$ & $297(279-322)$ \\
3. Cusp & 154 & $12.54( \pm 0.58)$ & $297(266-327)$ \\
$\begin{array}{l}\text { 4. Grove } \\
\begin{array}{l}\text { 5. Parallel to } \\
\text { occlusal }\end{array}\end{array}$ & 28 & $12.39( \pm 0.48)$ & $301(327-390)$ \\
\hline
\end{tabular}

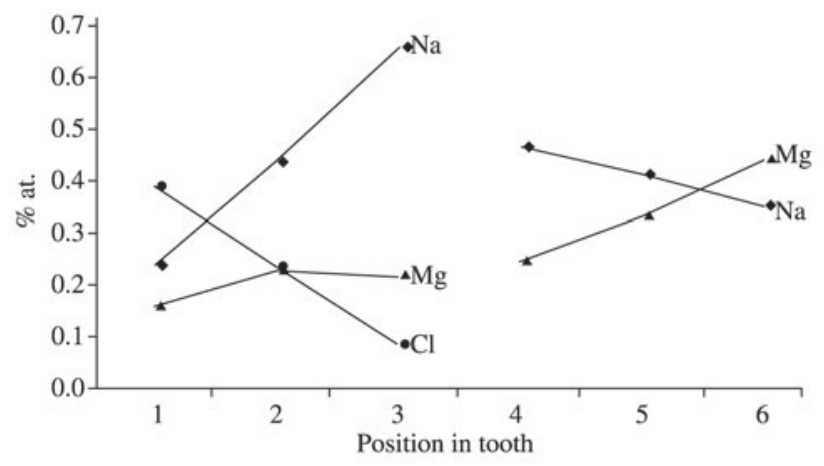

Figure 5. Graphics for the minor elements ( $\mathrm{Na}, \mathrm{Mg}$, and $\mathrm{Cl})$ detected in the human tooth from the outer enamel surface (number 1) to dentin inner layer (number 6) through the EDJ (numbers 3 and 4). See Table 4 . Note the increment of $\mathrm{Na}$ and the decrement of $\mathrm{Cl}$ from the outer enamel surface to the EDJ. In dentin $\mathrm{Na}$ shows a decrement after the EDJ, and $\mathrm{Cl}$ is not present. $\mathrm{Mg}$ concentration shows an increment from the outer enamel surface to the inner dentin surface. Each number represents a multiple of $40 \mu \mathrm{m}$ approximately.
Table 3. Main VHN values for the five zones from the 7 samples analyzed. Zone 1 (cervical) was not included because its very small thickness allowed only few good indentations (always less than four). The value for EDJ represents indentations in enamel, $20 \mu \mathrm{m}$ away from the junction.

\begin{tabular}{ccccc}
\hline & Zone 2 & Zone 3 & Zone 4 & Zone 5 \\
\hline \multirow{6}{*}{ Enamel } & & & 297 & 350 \\
& & 297 & 339 & 350 \\
& & 274 & 339 & 350 \\
& 290 & 322 & 322 & 383 \\
& 290 & 322 & 322 & 383 \\
& 290 & 322 & 322 & 383 \\
& 290 & 322 & 322 & 383 \\
& 274 & 322 & 322 & 350 \\
& 290 & 322 & 397 & 350 \\
EDJ & 254 & 297 & 297 & 350 \\
& 274 & 297 & 322 & 350 \\
Dentin & 193 & 160 & 297 & 350 \\
\hline & 46.7 & 51.5 & 51.5 & 57.5 \\
& 46.7 & 51.5 & 49.8 & 55.5 \\
& 46.7 & 51.5 & 49.8 & 55.5 \\
\hline
\end{tabular}

tite; that is, more $\mathrm{Ca}$ than $\mathrm{P}$ (Table 4). $\mathrm{Na}, \mathrm{Cl}$ and $\mathrm{Mg}$ were also detected ${ }^{24}$ (Fig. 5). In general, in enamel $\mathrm{Na}$ and $\mathrm{Mg}$ showed a minimum in the enamel outer surface, but increased continuously until reach the EDJ. Ca and $\mathrm{P}$ remained almost constant all the enamel thickness. $\mathrm{Cl}$ was higher detected in the enamel outer surface than in EDJ. In dentin, the ratio $\mathrm{Ca} / \mathrm{P}$ was found around 1.5 (Table 4 ); that is, more $\mathrm{P}$ in enamel than in dentin; $\mathrm{Cl}$ was not presented, $\mathrm{Mg}$ increased from EDJ to the inner surface, and $\mathrm{Na}$ decreased in these sites (Fig. 5). It is also worth noting the behavior of $\mathrm{C}$ and $\mathrm{O}$ : in dentin the percentage of $\mathrm{C}$ and $\mathrm{O}$ is higher than in enamel. This is an indication of more weight percentage of organic material in dentin than in enamel, as it is well known.

\section{Discussion}

According with our results, in tooth hardness studies the Vicker indenter is more useful than the Knoop's because a square shape has to be always conserved; and close to the outer surface and the EDJ a small elongation of the diagonals of the indentations, that produce errors in hardness measurements, is easily detected. Therefore, we propose that the Vicker indenter has to be used always in the tooth hardness studies.

We statistically found any significative hardness difference in the same zone of the sound tooth samples analyzed but only among the different zones of the same tooth itself, 
Table 4. EDS results from enamel and dentin. Data in at.\% and they are the main values from 3 samples analyzed. EDS analysis was carried out from the outer enamel surface to EDJ in enamel, and from EDJ to the inner dentin layer in dentin. The data in the two EDJ columns were taken inside enamel and dentin respectively, but $20 \mu \mathrm{m}$ away from the EDJ in each case. The data for $\mathrm{Na}, \mathrm{Cl}$ and $\mathrm{Mg}$ are graphically shown in Fig. 5.

\begin{tabular}{ccccccc}
\hline & \multicolumn{3}{c}{ ENAMEL } & \multicolumn{3}{c}{ DENTIN } \\
\hline Element & Outer Surface & Middle & EDJ & EDJ & Middle & Inner \\
$\mathrm{C}$ & $38.59(1.60)$ & $36.28(0.84)$ & $37.05(1.51)$ & $59.00(4.45)$ & $52.27(3.16)$ & $49.84(0.88)$ \\
$\mathrm{O}$ & $32.59(0.91)$ & $34.21(0.67)$ & $34.51(0.96)$ & $30.67(1.87)$ & $30.57(2.14)$ & $33.54(0.51)$ \\
$\mathrm{Na}$ & $0.24(0.08)$ & $0.44(0.13)$ & $0.66(0.09)$ & $0.47(0.08)$ & $0.42(0.07)$ & $0.36(0.07)$ \\
$\mathrm{Mg}$ & $0.16(0.03)$ & $0.23(0.07)$ & $0.22(0.03)$ & $0.25(0.04)$ & $0.34(0.06)$ & $0.45(0.05)$ \\
$\mathrm{P}$ & $10.67(0.34)$ & $10.86(0.14)$ & $10.46(0.26)$ & $4.41(0.99)$ & $6.23(0.46)$ & $6.32(0.15)$ \\
$\mathrm{Cl}$ & $0.39(0.46)$ & $0.25(0.08)$ & $0.09(0.04)$ & - & - & - \\
$\mathrm{Ca}$ & $17.36(0.44)$ & $17.74(0.28)$ & $16.99(0.33)$ & $5.19(1.65)$ & $9.15(0.70)$ & $9.50(0.27)$ \\
$\mathrm{Ca} / \mathrm{P} \mathrm{Ratio}$ & $1.63(0.02)$ & $1.63(0.01)$ & $1.62(0.02)$ & $1.16(0.11)$ & $1.47(0.05)$ & $1.50(0.01)$ \\
\hline
\end{tabular}

according with Tables 2 and 3 . We found hardness values in the range from 270 to $360 \mathrm{VHN}$ for enamel and from 50 to $60 \mathrm{VHN}$ for dentin; the differences depend on the zone evaluated. These results are similar to those reported by Craig and Peyton ${ }^{13}$, but in our case these VHN values are constant all along the enamel and dentin thicknesses for each evaluation zone. In conclusion, an slight increment in hardness was observed from zone 1 to zone 5; that is, from the cervical zone in longitudinal section to the transverse section, parallel to occlusal.

Some authors ${ }^{21}$ have indicated some variations in hardness from the tooth outer surface compared with those sites close to EDJ, similar to the ones reported in Table 2, but they have also obtained, significative increments in the SD values. Eventhough, they have reported bigger VHN values for the outer surface than for the EDJ, indicating, as Gustafson and Kling ${ }^{21}$, that these differences in hardness are produced by the wrinkled structure that prisms present in the outer surface. In this work, statistically speaking the hardness values remained constant along the enamel and dentin thicknesses respectively, and they only changed close to the EDJ for natural reasons: there is a gap of around $20 \mu \mathrm{m}$ before and after the EDJ where the indentation shape shows some of the irregularities indicated in Fig. 3. This gives place to lower hardness values such as those that they reported. We decide not to include these values in our measurements because they did not fulfill all the requirements to be accepted for a Vicker hardness analysis.

It is clear that the VHN difference between enamel and dentin is a result of the difference in the organic and inorganic materials content, as it is well known. However, according with our results, the VHN found in enamel and dentin themselves are not influenced by the presence of the minor elements $\mathrm{Na}, \mathrm{Cl}$ and $\mathrm{Mg}$, as some authors have indicated $^{18-22}$, but only for the percentage of mineralization in these tissues.

\section{Conclusions}

The tooth Vicker hardness values do not show statistically any change from the outer enamel surface to EDJ, and from EDJ to the inner dentin surface; they remain constant all along enamel and dentin thickness in the zone under analysis. The hardness is only bigger along the transversal section than along the longitudinal section, and slightly bigger from zone 1 to zone 5. The VHN difference between enamel and dentin is a result of the percentage of mineralization they present.

\section{Acknowledgements}

We acknowledge the technical help from R. Trejo, J. Cañetas, R. Hernández, P. Mexia, C. Magaña, M. Aguilar, C. Zorrilla, S. Tehuacanero, L. Rendón, and A. Sánchez. We thank the economical support from DGAPAUNAM (Project IN-104902).

\section{References}

1. Le Geros, R.Z. Calcium phosphates in oral biology and medicine, Howard M. Myers, Ed., San Francisco, California, 1991.

2. Reyes-Gasga, J.; Alcantara-Rodriguez, C.M.; GonzalezTrejo, A.M.; Madrigal-Colin, A. Acta Microscopica, v. 6, p. 24-38, 1997.

3. Kinney, J.H.; Balooch, M.; Marshall, S.J.; Marshall. G.W.; Weihs, T.P. Archs Oral Biol., v. 41, p. 9-13, 1996.

4. Meredith, N.; Sherriff, M.; Setchell, D.J.; Swanson, S.A.V. Archs, Oral Biol. v. 41, p. 539-545, 1996.

5. Marshall, G.W. Quintessence Int. v. 24, p. 606-617, 1993.

6. Fosse, G.; Saele, P.K.; Eibe, R. Acta Odontol. Scand, v. 50, p. 201-210, 1992.

7. Garberoglio, R.; Brannstrom, M. Archs Oral Biol., v. 21, p. 355-362, 1976. 
8. Stephen, N.; Wei, H.Y.; Koulourides, V. J. Dent. Res., v. 51, p. 648-651, 1972.

9. Taketa, F.; Perdue, H.S.; O'Rourke, W.F.; Sievert, H.W.; Phillips, P.H. J. Dent. Res., v. 36, p. 739-742, 1957.

10. Totah, V.P. J. Dent. Res., v. 21, p. 99-104, 1942.

11. Caldwell, R.C.; Muntz, M.L.; Gilmore, R.; Pigman, W. J. Dent. Res., v. 36, p. 732-737, 1957.

12. Sweeney, W.T. J. Dent. Res., v. 21, p. 303-310, 1942.

13. Craig, R.G.; Peyton, F.A. J. Dent. Res., v. 37, p.661668, 1958.

14. Collys, K.; Slop, D.; Cleymaet, R.; Coomanss, D.; Michotte, Y. Dent Mater., v. 8, p. 332-335, 1992.

15. Ryge, G.; Foley, D.E.; Fairhurst, C.W. J. Dent. Res. v. 40, p. 1116-1121, 1961.

16. Wilson, T.G.; Love, B. Am. J. Orth. and Dentofacial Orthop, v. 107, p. 379-381, 1995.
17. Gaspersic, D. J. Oral Pathol. Med., v. 24, p.153-158, 1995.

18. Robinson, C.; Weatherell, J.A.; Hallsworth, A.S. Caries Res., v. 15, p. 70-77, 1981.

19. Kodaka, T.; Debari, K.; Yamada, M.; Kuroiwa, M. Caries Res., v. 26, p. 139-141, 1992.

20. Davidson, C.L.; Hoekstra, I.S.; Arends, J. Caries Res., v. 8, p. 135-144, 1974.

21. Gustafson, G.; Kling, O. Odontol. Tskr., v. 56, p. 23-30, 1948.

22. Herkströter, F.M.; Witjes, M.; Ruben, J.; Arends, J. Caries Res., v. 23, p. 342-344, 1989.

23. McColm, I.J. Introduction and overview in ceramic hardness, Plenum Press, New York, 1990.

24. Robinson, C.; Weatherell, J.A.; Hallsworth, A.S. Caries Res., v. 15, p. 70-77, 1981. 